DOI https://doi.org/10.18551/rjoas.2017-09.18

\title{
MANAGEMENT OF ACCELERATION TIME BY USING TIME COST TRADE OFF METHOD ON CONSTRUCTION PROJECT OF INTEGRATED OFFICE OF SAMARINDA
}

\author{
Rio Wahyu Yusuf*, Putranto Edi Hargono Dwi, Mulyadi Lalu \\ Study Program of Civil Engineering, Concentration on Construction Management, \\ National Institute of Technology, Malang, Indonesia \\ *E-mail: wahyusufrio@gmail.com
}

\begin{abstract}
Time and cost analyzes were conducted in this research; which were required in the application of Time Cost Trade Off (TCTO) in finishing construction project of Samarinda Integrated Office. In order to realize the picture of the acceleration, it began with the creation of Critical Path Method (CPM) network to know the existence of critical path. Moreover, the application of TCTO method was conducted to find the cost slope value from each of these critical activities. In order to realize the acceleration, the compression on critical work items was conducted starting from the lowest cost slope value. The result of this research produces two alternatives. Alternative I obtained the overtime over one activity from 1 hour to 4 hours, the time and cost were found in the 2-hour-overtime alternative to ACP plank list job, it obtained the time for 408 days from the normal amount for 410 days. Meanwhile, for the cost, it obtained IDR 41.356.071.000,00 from the total normal cost of IDR 40.623.401.000,00 or there was additional cost of IDR 732.670.000,00. Whereas in alternative II, it was obtained overtime of some activities from 1 hour to 4 hours overtime, time and cost were obtained in 1-hour overtime on ground foundation work, the ground work of the sand under the foundation, ACP plank list, window door, and dry hand, with 398 days and a fee of IDR 41.440.678.000,00 (there was additional fee of IDR 817.277.000,00).
\end{abstract}

\section{KEY WORDS}

Planning, scheduling, financing, crashing, time cost trade off.

The present development of construction services in Indonesia is rapidly progressing with the large number of projects are undertaken on a large scale, whether it is built by the government, the private sector, or a combination of both. By the growing development in Indonesia, especially in the area of Samarinda, competition among contractors who are engaged in the construction world becomes more competitive, so that time factor is very important in addition to cost factor in a project completion, (Sheremata, 2000). Discrepancy frequently occurs in the implementation of construction projects between the time schedule and the realization in the field, so that it may cause delays, (Feng et al, 1997). The delays are caused by lack of discipline of human resources, lack of equipment, delays in material delivery and delays in the costs of construction implementation, (El-Rayes and Kandil, 2005). Some ways are made to overcome the delays, such as holding a shift job, extending the work time (overtime), using more productive tools, increasing the number of labor, using materials that can make the work faster, all of which are intended to speed up the duration of project implementation, (Cohen et al, 1996). Among these alternative acceleration, overtime alternative is better to be applied, because extending work time may help in reducing the overall time of an activity, it can reduce the duration of an activity by $33 \%$ (Ward and Chapman, 2003).

The research of this case is the construction project of Integrated Office of Samarinda. This project was implemented with implementation time of 410 days of the calendar, and the budget was Rp. 40,623,400,000.00 (forty billion six hundred twenty three million and four hundred thousand rupiah). This project was planned from October 24, 2014 and completed on December 7, 2016, but in its implementation the project was experiencing delays. On October 24, 2014 the project should be workable, but in its implementation, the project could 
be conducted on November 1, 2014. This was due to the late availability of the Spun Pile D 45 foundation, so it caused delay to other activities.

According to the regulation of project delay fines, Article 120 of Presidential Decree No. 70 of 2012, concerning the delay sanction, it says that the provider of goods/services who are late in completing the work within the time stipulated in the contract due to the mistake of the provider of goods/services, shall be liable to a fine of 1/1000 (one thousandth) of the contract value or the contractual portion value for each day of delay.

According to the matter, to restore the level of progress of the project to the original time schedule, it would require an effort of acceleration, although it will cause the rising cost of the project, (Tavana et al, 2014). Such efforts can be analyzed by exchanging cost against time by using Time Cost Trade Off (TCTO) method. The TCTO method aims to make an attempt for an acceleration of an activity duration, by conducting tests for all critical activities, so that the acceleration is followed by an increase in the total project cost, which is kept as minimum as possible.

\section{LITERATURE REVIEW}

Network Planning. Suharto (2001) stated that principally, network planning is a dependency relationship between the parts of the work that is illustrated in the network diagram, so that it is known which parts of work should take precedence and which work should wait for the completion of another work.

CPM Calculation Procedure. Suharto (2001) mentioned that Critical Path Method (CPM) uses counting forward and counting backward. Counting forward is intended to find out the earliest time to start and end each work without delay. While counting backward is intended to determine the time or the latest date to start and end of each work, without delaying the overall project completion time, which have been resulted from the counting forward, (Robertson and Ulrich, 1998).

Float and Critical Track. Suharto (2001) argued that float is the allowed time where the works can be delayed. In the CPM method, there are three types of floats; they are Total Float (TF), Free Float (FF), and Interferent Float (IF).

Project Costs. American Association of Cost Engineering (1992) stated that there are several types of costs related to the cost of construction project (Hegazy, 1999), they can be divided into two types, as follows:

- Indirect costs

Indirect costs are costs that are indirectly related to the construction, but it must exist and can not be separated from the project. Indirect costs include overhead costs, profit, unexpected costs, and value added tax (VAT).

- Direct costs

Direct costs are costs that are incurred and directly related to ongoing project activities. Direct costs include material costs, labor costs, and tool costs.

Time Cost Trade Off. Time cost trade off is a deliberate, systematic and analytical process by doing testing of all works in a project that focus on the work that is on the critical track, (Roemer et al, 2000). Suharto (2001) argued that the total project cost is the sum of both direct and indirect costs. The amount of this cost depends on the duration of the project completion. Both of them change according to the time and progress of the project. Further analysis of the relationship between time and cost of a work are mentioned below.

- Normal Duration (ND);

- Crash Duration (CD);

- Normal Cost (NC);

- Crash Cost (CC).

Compression of Time Cost Trade Off. Soeharto (2001) argued that in accelerating the completion of a project by compressing the duration of activities, efforts are made to make the additional costs as minimum as possible. Control of the cost that is conducted is direct costs, because this cost will increase if the duration is decreased. Compression is only 
conducted on activities that are on the critical track. If compression is conducted on activities that are not on the critical path, the overall project completion time will remain the same. Compression is conducted firstly to the activity that has the lowest cost slope and is on the critical track.

\section{METHODS OF RESEARCH}

This research is a quantitative research that was conducted on construction project of an Integrated Office. This project had a budget of IDR 40.623.400.000,00 with normal implementation time for 410 days of the calendar. This research uses primary and secondary data. Primary data includes data that were obtained from the main source or from the project. The primary data sources are from the employees of the company and construction project of Integrated Office. The primary data are obtained by observation and interviews with the head of the project about the overhead cost. To support the primary data and become input and research reference, secondary data are obtained through working drawings, network planning, Budget Plan (RAB), S curve (Schedule), core personnel data, and Samarinda City Map.

Data are collected through the interviews to the head of the project that is directly involved in project implementation. The collected data are processed, related to the identification of critical track and project cost that include direct costs and indirect costs, before analyzing TCTO on the construction project of Integrated Office Samarinda. Data analysis technique were used in this study includes the calculation of the number of activities that are on the critical track in the network planning, direct costs and indirect costs, and the setting of the scenario analysis of TCTO method. In the implementation of this scenario, TCTO used the alternative of work time.

Acceleration of Network Planning. After compression of overtime 1 hour to 4 hours, one of the acceleration of overtime alternative is advantageous in terms of time and cost. In terms of time, the fastest and the most effective cost will be made again in the acceleration of network planning, (Haga and Marold, 2004). The steps in preparing the CPM network planning are as follows:

- Collect secondary data from the project in the form of curve $S$ so that it is the reference material of duration.

- Identify the scope of the project and break it down into components of activity.

- Compile the components of activities on the project in the order of dependence logic into network planning.

- Provides an approximate time curve according to the duration of the project for each job.

- Identify the critical track, float, and duration of the project.

\section{RESULTS AND DISCUSSION}

Identify the Critical Track. Construction project of Integrated Office of Samarinda consisted of four main works. Each part as composed of more specific work items. In scheduling the project, time schedule was used (curve S). The project was scheduled for completion in 410 days of calendar, starting from October 24, 2014 until December 7, 2016, but in its implementation, the project was delayed. On October 24, 2014 the project should had been workable but it was started on November 1, 2014.

Identification of Project Costs. In construction project of Integrated Office of Samarinda, the contract value is IDR $40.623 .401 .000,00$. In this case, analyzing the acceleration of the project time may affect the cost of the project itself, then project costs will first be detailed with indirect and direct costs, as a follow up of the TCTO method.

Indirect Costs. Indirect costs are costs that are not directly related to construction, but it must exist and can not be separated from the project. Indirect costs include overhead costs, profit, unexpected costs and value added tax (VAT) which can be explained as follows. 
Overhead Costs. Overhead costs are the salaries of project staff and the cost of field facilities. The overhead cost that has been identified in the construction project of Integrated Office of Samarinda is IDR $890.000,00$.

Table 1 - Total Overhead

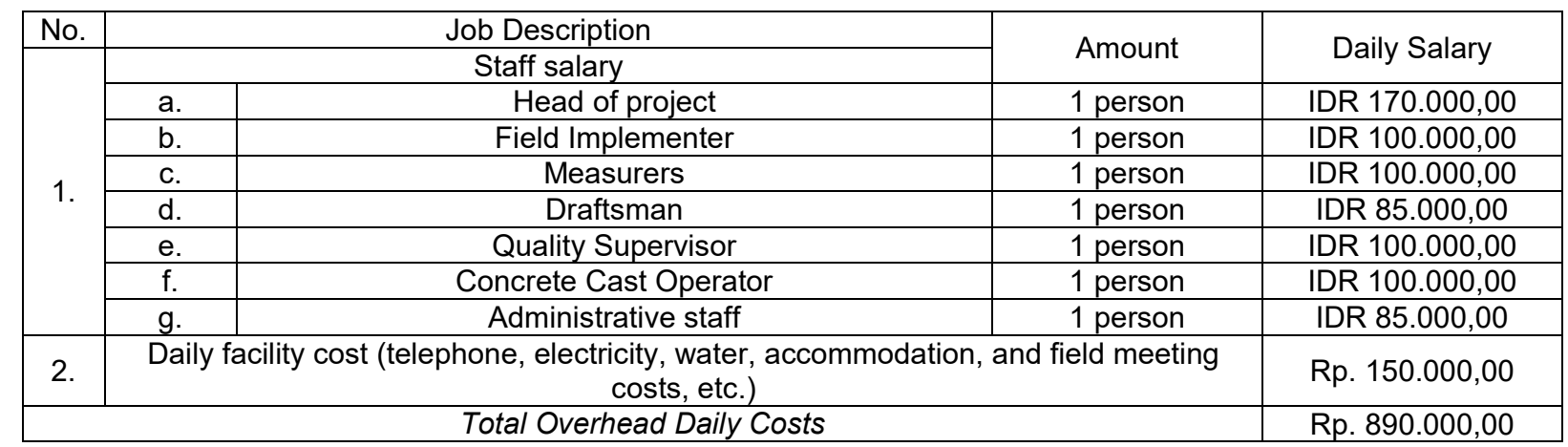

Staffs, who are directly involved in overtime work at the project site are field implementers and quality supervisors.

Details of overtime costs for staffs in the field are as follows:

Total of staff salary per day $=$ Salary of the implementers + quality supervisors $=R p .200 .000,00$

$$
\text { Total of staff salary per hour }=\frac{\text { Total salary per hour }}{\text { Normal worktime }}=\frac{\text { IDR 200.000,00 }}{7 \text { Hours }}=\text { IDR 28.571,43 }
$$

So, the total overtime salary of the staff per day from 1 hour to 4 hours is as follows:

Total 1 hour overtime salary of the staff $=\left(J k_{1} \times 1.5 \times\right.$ total salary per hour $)$ $=(1$ hour $\times 1.5 \times$ IDR 28.571,43) $=$ IDR 42.857,14

Total 2 hours overtime salary of the staff $=\left(J k_{1} \times 1.5 \times\right.$ total salary per hour $)+\left(J k l_{1} \times 2 \times\right.$ total salary per hour $)$ $=(1$ hour $\times 1.5 \times$ IDR 28.571,43) + (1 hour $\times 2 \times$ IDR 28.571,43) $=$ IDR 100.000,00

Total 3 hours overtime salary of the staff $=\left(J k_{1} \times 1.5 \times\right.$ total salary per hour $)+\left(J k l_{2} \times 2 \times\right.$ total salary per hour $)$ $=(1$ hour $\times 1.5 \times$ IDR 28.571,43) + (2 hours $\times 2 \times$ IDR 28.571,43) $=$ IDR 157.142,86

Total 4 hours overtime salary of the staff $=\left(J k_{1} \times 1.5 \times\right.$ total salary per hour $)+\left(J k l_{3} \times 2 \times\right.$ total salary per hour $)$ $=(1$ hour $\times 1.5 \times$ IDR 28.571,43) + (3 hours $\times 2 \times$ IDR 28.571,43) $=$ IDR 214.285, 71

Advantages. Contractor profit is profit earned on a project that has the difference between the Budget Plan with the Budget Implementation Plan, (Dickinson et al, 2001). Profit is divided into two kinds: gross profit and net profit. The gross profit is $10 \%$ of the real cost, which includes the overhead cost that is borne by the contractor.

Table 2 - Real Cost

\begin{tabular}{|c|c|c|c|}
\hline No. & Job Description & \multicolumn{2}{|c|}{ Total price } \\
\hline 1. & Preparatory Work & IDR & $77.990 .750,00$ \\
\hline 2. & Structural Work & IDR & $18.021 .465 .129,90$ \\
\hline 3. & Architectural Work & IDR & $6.631 .945 .075,55$ \\
\hline 4. & Mechanical and Electrical Work & IDR & $12.198 .963 .200,00$ \\
\hline \multicolumn{2}{|r|}{} \\
\hline
\end{tabular}

Here is the calculation of the gross profit and net profit on the project below:

Gross profit $=$ Real cost $\times 10 \%=I D R 36.930 .364 .155,45 \times 10 \%=I D R 3.693 .036 .415,55$

Net profit $=$ Gross profit - (Overhead cost per day $x$ Implementation time)

$=I D R$ 3.693.036.415,55 $-(I D R 890.000,00 \times 410)=I D R 3.328 .136 .415,55$ 
Unexpected costs. Based on the letter of chartering agreements (contracts), the amount of unexpected costs are $2 \%$ of the real cost. The calculation of the unexpected cost of the project is as follows:

$$
\begin{gathered}
\text { Unexpected costs }=\text { Real cost } \times 2 \%=I D R 36.930 .364 .155,45 \times 2 \%=I D R 738.607 .283,11 \\
\text { Unexpected costs per day }=\frac{\text { Unexpected Cost }}{\text { Time Implementation }}=\frac{\text { IDR } 738.607 .283,11}{410 \text { days }}=I D R 1.801 .481,18
\end{gathered}
$$

Value Added Tax (VAT). Based on the letter of chartering agreements (contracts) of the cost of the Value Added Tax (VAT) is $10 \%$ of the real cost that is borne by the contractor. The calculation of the amount of VAT cost on the project is as follows:

Value Added Tax $($ VAT $)=$ Real cost $\times 10 \%=$ IDR 36.930.364.155,45 x 10\% = IDR 3.693.036.415,55 as follows:

So the indirect costs of the construction project of Integrated Office of Samarinda are Indirect costs $=($ implementation time $x($ overhead costs per day + unexpected costs per day $))+$ net profit + VAT
$=(410$ days $x($ IDR 890.000,00 + IDR 1.801.481,18) $)+$ IDR 3.328.136.415,55 + IDR 3.693.036.415,55
$=$ IDR 8.124.680.115,20

Direct Cost. Direct costs are costs that are directly related to project work in the field. The direct costs in this project are the cost of workers' salary and material costs.

$$
\begin{gathered}
\text { Direct cost }=\text { Real cost }- \text { gross profit }- \text { unexpected costs of } 2 \% \\
=I D R 36.930 .364 .155,45-I D R 3.693 .036 .415,55-I D R 738.607 .283,11=I D R 33.237 .291 .710,28
\end{gathered}
$$

The Implementation of Time Cost Trade Off Method. The steps of applying TCTO method on alternative calculation of overtime changes, which are to be tested from 1 hour to 4 hours of maximum limit, will be given examples for excavation work of foundation ground in the calculation of 2 hours overtime as follows:

Normal duration is the period of time that is required to complete the work normally. Crash duration or the shortened period is the shortest time to complete a job that is technically still allowed to be accelerated. After the daily productivity after the crash increases, the time that is required to complete a job will be increased. Here is the calculation of crash duration for some work.

$$
\text { Crash Duration of foundation soil excavation }=\frac{\text { Volume }}{\text { Daily productivity after crash }}=\frac{468,90 \mathrm{~m}^{3}}{1.201,11 \mathrm{~m}^{3} / \mathrm{day}}=0.39 \text { day }
$$

Normal cost is the cost required to complete the work at the normal time period. The following is a normal cost calculation for some work, as follows:

$$
\begin{aligned}
& \text { Normal Cost of foundation soil excavation }=\text { ND } \times \text { Normal Cost of worker per day } \\
& =0.48 \text { day } \times \text { IDR } 62.325 .183,21=I D R 29.892 .375,00
\end{aligned}
$$

Crash Cost or cost for a shortened time is the amount of costs / salary of workers that are required to complete a work with an accelerated time period (Crash Duration). Here's a crash cost calculation of some works:

$$
\begin{gathered}
\text { Crash Cost of foundation soil excavation }=\text { Crash Cost of worker per day } \times \text { Crash Duration (CD) } \\
=I D R 93.487 .774,82 \times 0.39 \text { day }=I D R 36.496 .504,36
\end{gathered}
$$

Cost Slope is the increase of the direct costs to speed up an activity per unit of time. The following is the calculation of Cost Slope for some works, as follows:

$$
\text { Cost Slope (CS) of foundation soil excavation }=\frac{\text { Crash Cost }- \text { Normal Cost }}{\text { Normal Duration }- \text { Crash Duration }}=I D R \text { 74.011.155,07 }
$$


In the CPM method there are two estimates of time and cost for each activity in the network planning. Both of these estimates are approximate completion time and costs that are normal (normal estimate) and the estimated time of completion and costs that are accelerated (crashes estimate).

In the process of speeding up the project completion time by emphasizing the duration (compression), it is strived for additional costs to be as minimum as possible. Compression is conducted on all works that are on the critical track and are started from the works that have the lowest value of cost slope. From the steps of the compression, it will be sought for the fastest time of completion of the total project cost to be as minimum as possible.

The analysis of normal step:

1. Age of the project $=410$ days

2. Direct cost $=$ IDR $32.237 .291 .710,28$

3. Indirect costs $=$ IDR 8.124.680.114,20

4. Total cost $=$ Direct Cost + Indirect Cost $=$ IDR 40.623.400.000,00

The analysis of compression step I:

1. Cost Slope $=$ IDR 74.011.155,07

2. Normal Duration $=0.48$ day

3. Crash Duration $=0.39$ days

4. Total $\mathrm{Crash}=$ Normal Duration - Crash Duration $=0.09$ day

5. Total duration of the project $=$ Age of the project - Total Crash $=409.91$ day

6. Additional fee $=$ Cost Slope $\times$ Total Crash $=$ IDR 6.604.129,36

7. Direct cost $=$ Normal direct cost + Additional cost $=R p 33 \cdot 242 \cdot 130 \cdot 388,08$

8. Additional staff overtime charge $=$ Overtime Cost for staff $/$ day $\times$ Crash Duration $=$ IDR $39.038,80$

9. Indirect costs $=($ Total project duration $x$ (Daily overhead cost + Unexpected daily cost $))+$ Net profit + VAT + Additional overtime staff costs = IDR 8.124.478.987,99

10. Total Cost $=$ Direct Cost + Indirect Costs $=$ IDR 41.366.609.000,00

11. Added Cost $=$ Total accelerated costs - Total normal costs $=$ IDR $743.208 .000,00$

Accelerated Adjustment to Target. In this case, a very advantageous step in terms of time is on alternative II, it is to have for 7 activities for 1 hour. The critical activity that has overtime for over 1 hour is the board works, spun pile stakes, sand excavation under the foundation, plank list works, installation of $9 \mathrm{~mm}$ gypsum ceiling, window doors, and dry hand. The cost is IDR 41.440.678.000,00 from the total normal cost of IDR $40.623 .401 .000,00$ or the additional cost of IDR $817.277 .000,00$. After that, it looks for suitable schedule with 8 days of delays, and then it looks for acceleration for 8 days. It is conducted with the addition of 1 hour of overtime work. It is not having overtime work for the installation of $9 \mathrm{~mm}$ gypsum plafond and dry hand activities.

Table 3 - Recapitulation of Overtime Alternative

\begin{tabular}{|c|c|c|c|c|c|c|}
\hline No. & & vertime & Time & Acceleration & Total Cost & Additional Cost \\
\hline 1 & & Normal & 410 & - & IDR 40.623.401.000,00 & - \\
\hline 2 & \multicolumn{6}{|c|}{ Alternative I } \\
\hline & $a$ & 1 Hour & 408 & 2 & IDR 41.356.736.000,00 & IDR 733.335.000,00 \\
\hline & $\mathrm{b}$ & 2 Hours & 407 & 3 & IDR 41.356.071.000,00 & IDR 732.670.000,00 \\
\hline & $\mathrm{C}$ & 3 Hours & 407 & 3 & IDR 41.357.156.000,00 & IDR 733.755.000,00 \\
\hline & $d$ & 4 Hours & 406 & 4 & IDR 41.359.782.000,00 & IDR 736.381.000,00 \\
\hline 3 & \multicolumn{6}{|c|}{ Alternative II } \\
\hline & $a$ & 1 Hour & 398 & 12 & IDR 41.440.678.000,00 & IDR 817.277.000,00 \\
\hline & $\mathrm{b}$ & 2 Hours & 390 & 20 & IDR 42.380.342.000,00 & IDR 1.756.941.000,00 \\
\hline & $\mathrm{C}$ & 3 Hours & 385 & 26 & IDR 44.315.223.000,00 & IDR 3.691.822.000,00 \\
\hline & $d$ & 4 Hours & 382 & 29 & IDR 47.170.344.000,00 & IDR 6.546.943.000,00 \\
\hline
\end{tabular}

After conducting acceleration by the addition of overtime hours of 1 hour up to 4 hours, acceleration by the addition of 1 hour worktime was chosen with the total cost of IDR 41.440.677.900.01. Then from the acceleration of 1 hour overtime, acceleration is tried again to get the results of 8 days acceleration that aims for the on time implementation of activities according to the time schedule. 
From the 8 days acceleration, it is obtained values for total cost of IDR 41.449.583.302,64 which has a greater value than 12 days of acceleration. So 12 days acceleration is chosen to avoid the amount of additional costs due to the acceleration from IDR 826.182.000,00 to IDR 817.277.000,00. Thus, the project completion time of 398 days can be rescheduled (rescheduling) by using network planning.

\section{CONCLUSION AND RECOMMENDATIONS}

With the addition of 1 hour overtime, the acceleration time for completion of the construction project is 12 days. Or the project completion duration is 398 days from the remaining 402 days of completion target: total cost needed after the acceleration by using TCTO is IDR 41.440.678.000.00 of the total normal cost of IDR 40.623.401.000,00; additional cost is IDR 817.277.000,00.

For the construction entrepreneur party, if the project certainly will not experience delay of a predetermined schedule on specific contractual agreements, but if accelerated step is conducted, then in the implementation of TCTO method, only one of the critical activities can have the overtime. It is because, in addition to completing the project faster, in terms of the cost of acceleration, it will require a little additional cost.

When delay is occuring by pursuing a predetermined schedule of contractual agreements, it is advisable to apply TCTO methods to some critical activities. This is because in addition to completing the project on time or faster, the required cost for the acceleration can be clearly identified through the TCTO method approach.

For the next researcher, it is suggested that the research can do the optimization of time and cost and development of another acceleration method, and using the latest SNI for its resource requirement.

\section{REFERENCES}

1. AACE (1992). Skills and Knowledge of Cost Enggineering, 3rd Ed., ACE, West Virginia.

2. Cohen, M. A., Eliasberg, J., \& Ho, T. H. (1996). New product development: The performance and time-to-market tradeoff. Management Science, 42(2), 173-186.

3. Dickinson, M. W. (2001). Technology portfolio management. IEEE Transactions on engineering management, 48(4), 518-527.

4. El-Rayes, K., \& Kandil, A. (2005). Time-cost-quality trade-off analysis for highway construction. Journal of construction Engineering and Management, 131(4), 477-486.

5. Ervianto, WI 2004, Teori Aplikasi Manajemen Proyek Konstruksi, Andi, Yogyakarta.

6. Feng, C. W., Liu, L., \& Burns, S. A. (1997). Using genetic algorithms to solve construction time-cost trade-off problems. Journal of computing in civil engineering, 11(3), 184-189.

7. Haga, W. A., \& Marold, K. (2004, June). A simulation approach to the PERT/CPM timecost trade-off problem. Project Management Institute.

8. Hegazy, T. (1999). Optimization of construction time-cost trade-off analysis using genetic algorithms. Canadian Journal of Civil Engineering, 26(6), 685-697.

9. Robertson, D. (1998). Planning for product platforms. Sloan management review, 39(4), 19.

10. Roemer, T. A., Ahmadi, R., \& Wang, R. H. (2000). Time-cost trade-offs in overlapped product development. Operations Research, 48(6), 858-865.

11. Sheremata, W. A. (2000). Centrifugal and centripetal forces in radical new product development under time pressure. Academy of management review, 25(2), 389-408.

12. Soeharto, I 2001. Manajemen Proyek - Dari Konseptual Sampai Operasional, Jakarta.

13. Tavana, M. (2014). A new multi-objective multi-mode model for solving preemptive tradeoff project scheduling problems. Expert Systems with Applications, 41(4), 1830-1846.

14. Ward, S., \& Chapman, C. (2003). Transforming project risk management into project uncertainty management. International journal of project management, 21(2), 97-105. 